\title{
PENGETAHUAN MASYARAKAT TENTANG TAMAN OBAT KELUARGA DI NGLINGGI, KLATEN SELATAN
}

\author{
Susilo Yulianto \\ Kementerian Kesehatan Politeknik Kesehatan Surakarta Jurusan Jamu
}

\begin{abstract}
The Knowledge, People, TOGA. Family Medical Plants (TOGA) is one of many traditional medication that usedfor a long time in Indonesia. The successful of this family medical plants programvery depends with people's knowledge about every single plants that can used asherbal medicine, especially the one with empirical evidence. Beside of that, alsodepends with how people use that herbal medicine for each different case.This research is intended to disclose the description of people's knowledge andbehaviour about family medical plants at Nglinggi, Klaten Selatan. The present research deploy descriptive method, with 30 respondents assample that selected with simple random sampling. Data collection is conductedtrough guiding interview with respondent and direct observation. Instrument thatused is questionnaire and camera for observation. The data shows that all of respondents agree using herbal medicine foralternative medication, but there are respondents whose not used herbal medicinefor daily medication.The conclusions drawm from this research is people's knowledge in Klaten is still undertarget, because of that we have to give these people more information abaout family medical plants (TOGA).
\end{abstract}

Keyword: Knowledge, People, TOGA.

Abstrak: Pengetahuan, Masyarakat, TOGA. Taman Obat Keluarga (TOGA) merupakan salah satu alternatif pengobatanyang telah lama dilakukan oleh masyarakat Indonesia secara tradisional.Keberhasilan pemanfaatan TOGA sangat dipengaruhi oleh pengetahuanmasyarakat mengenai manfaat dari setiap jenis tanaman yang berkhasiat obatterutama tanaman obat yang telah terbukti khasiatnya secara empiris. Selain itu jugadipengaruhi oleh cara penggunaan masing-masing tanaman obat untuk berbagaipenyakit yang berbeda.Penelitian ini bertujuan untuk mengetahui gambaran pengetahuan masyarakat mengenai Taman Obat Keluarga di Nglinggi, Klaten Selatan. Metode penelitian ini adalah deskriptif, dengan sampel sebanyak 30 responden yang diambil dengan teknik sampel acak sederhana. Pengumpulan datadilakukan secara wawancara langsung kepada responden dan observasi terbuka. Instrument penelitian yang digunakan antara lain adalah kuesioner dan kamera.Dari hasil penelitian didapatkan bahwa seluruh responden menyetujui pemakaian tanaman obat sebagai alternatif terapi, tetapi masih ada respondenyang belum memanfaatkan TOGA untuk pengobatan sehari-hari. Kesimpulan penelitian ini adalah bahwa pengetahuan masyarakat di Klaten, secara umum mengenai TOGA dan pemanfaatannya masih kurang, oleh sebab itu masih perlu ditingkatkan lagi melalui penyuluhan.

Kata Kunci : Pengetahuan, Masyarakat, TOGA. 


\section{PENDAHULUAN}

Pengetahuan masyarakat tentang tanaman obat keluarga beserta manfaat dan kegunaannya baik untuk upaya peningkatan kesehatan, mencegah dari penyakit, penyembuhan penyakit dan pemulihan sudah ada sejak jaman dahulu dan sudah digunakan oleh masyarakat luas. Saat ini juga masyarakat mulai menggunakan kembali tanaman obat keluarga untuk kesehatan mereka.

WHO (Word Health Organization) mencanangkan gaya hidup sehat dengan cara back to natureatau kembali ke alam. Anjurannya meningkatkan penggunaan makanan tinggi serat dari tumbuhan, tanpa bahan pengawet, pewarna, perasa, pengembang dan penguat aroma.

Dengan adanya anjuran tersebut pemerintah mulai mengembangkan TOGA, dengan harapan dapat menekan faktor pencetus timbulnya penyakit degeneratif dan dapat mempercepat proses penyembuhan bagi masyarakat yang sakit. Obat tradisional tetap menjadi pilihan masyarakat, baik di pedesaan maupun di perkotaan. Kita dengan mudah menjumpai penjual-penjual jamu gendong, yang menjajakan jamu untuk kesehatan dan menyegarkan. Bahkan kios-kios obat tradisional sekarang ini mudah dijumpai, hal ini menandakan bahwasannya jamu dan obat-obatan tradisional sudah menjadi bagian dari kehidupan masyarakat.

Berbagai jenis taman obat keluarga, menambah ilmu pengetahuan dan kesehatan masyarakat. Indonesia merupakan salah satu negara yang memiliki ribuan jenis tanaman obat keluarga. Yang belum semuanya diketahui manfaat dan kegunaannya. Sampai saat ini TOGA, belum dimanfaatkan secara optimal. Untuk meningkatkan kualitas tanaman obat keluarga perlu kerjasama anatara pemerintah, masyarakat dan peran swasta, agar tanaman obat keluarga juga bisa dimanfaatkan untuk kalangan industri jamu sekaligus dapat meningkatkan perekonomian keluarga.

Pengetahuan masyarakat tentang TOGA tanaman obat keluarga yang bermanfaat untuk upaya promotif, preventif, kuratif, rehabilitatif serta untuk mempercantik diri, sudah dimanfaatkan sejak jaman nenek moyang kita sebelum pengobatan medis modern. Pengetahuan ini mereka dapatkan secara turun menurun.

Tradisi upaya penyembuhan yang dilakukan masyarakat sangat tergantung pada budaya yang berlaku di masyarakat tersebut. Pemahaman masyarakat tentang konsep sehat, sakit dan berbagai jenis tanaman obat keluarga melalui proses kemasyarakatan yang secara turun menurun diterapkan dan digunakan untuk kesehatan.

\section{METODE PENELITIAN}

Metode penelitian ini merupakan penelitian deskriptifyaitusuatu metode yang dilakukan dengan tujuan utama untuk membuat gambaranatau deskriptif tentang suatu keadaan secara objektif (Notoatmodjo,2005).

Penelitian ini menggunakan rancangancross sectional. Penelitian cross selectional adalah jenis penelitian yang menekankan waktu pengukuran/observasi hanya satu kali pada satu saat (Nursalam, 2008).

\section{HASIL PENELITIAN}

Hasil penelitian Pengetahuan Masyarakat Tentang TOGA di Nglinggi, Klaten Selatan,Tahun 2016, diperoleh hasil sebagai berikut: 
1. Umur responden sebagai berikut :

\section{Tabel 1}

Distribusi Frekuensi Menurut Umur Responden Tentang Tanaman Obat Keluarga Di Nglinggi, Klaten Selatan

\begin{tabular}{llll}
\hline No & $\begin{array}{l}\text { Umur } \\
\text { Responden }\end{array}$ & Jumlah & $\begin{array}{l}\text { Prosentase } \\
(\%)\end{array}$ \\
\hline 1. & $<20$ Tahun & 0 & 0 \\
2. & $\begin{array}{l}\text { 20- } 35 \\
\text { Tahun }\end{array}$ & 2 & 6,7 \\
3. & >35 Tahun & 28 & 93,3 \\
\hline & TOTAL & 30 & 100 \\
\hline
\end{tabular}

Berdasarkan tabel di atas maka dapat diketahui dari 30 responden yang diteliti, jumlah responden dengan umur $>35$ tahun merupakan kelompok umur yang terbanyak yaitu sebanyak 28 orang (93,3 \%), umur 20- 35 tahun sebanyak 2 orang $(6,7 \%)$ dan yang terkecil adalah umur $<20$ tahun sebanyak 0 orang.

2. Tingkat Pendidikan Responden :

Berdasarkan penelitian distribusi tingkat pendidikan responden adalah sebagai berikut :

Tabel 2

Distribusi Frekuensi Menurut Tingkat Pendidikan Responden Tentang Tanaman Obat Keluarga Di Nglinggi, Klaten Selatan

\begin{tabular}{clcc}
\hline No & $\begin{array}{l}\text { Tingkat } \\
\text { pendidikan }\end{array}$ & Jumlah & $\begin{array}{l}\text { Prosentase } \\
(\%)\end{array}$ \\
\hline 1. & SD & 5 & 16,7 \\
2. & SMP & 7 & 23,3 \\
3. & SMA & 11 & 36,7 \\
4. & PT & 7 & 23,3 \\
\hline & TOTAL & 30 & 100 \\
\hline
\end{tabular}

pendidikan diatas dapat diketahui bahwa mayoritas responden dengan pendidikan SMA sebanyak 11 orang $(36,7 \%)$, sedangkan yang terkecil pada responden dengan tingkat pendidikan SD yaitu sebanyak 5 orang $(16,7 \%)$, SMP sebanyak 7 orang $(23,3 \%)$ dan Perguruan Tinggi 6 orang $(23,3 \%)$.

3. Pengetahuan tentang jenis tanaman obat keluarga

Tabel 3

Distribusi Pengetahuan Masyarakat Tentang Jenis Tanaman Obat Keluarga Di Nglinggi, Klaten Selatan

\begin{tabular}{llcc}
\hline No & \multicolumn{1}{c}{ Pengetahuan } & F & \% \\
\hline 1. & Baik & 7 & 23, \\
2. & Cukup & 8 & 3 \\
3. & Kurang & 15 & 26, \\
& & & 7 \\
& & & 50 \\
\hline & & 30 & 100 \\
\hline
\end{tabular}

Berdasarkan tabel diatas dapat diketahui bahwa dari 30 responden didapatkan pengetahuan masyarakat tentang tanaman obat keluarga berada pada katagori kurang yaitu sebanyak 15 orang $(50 \%)$.

4. Pengetahuan tentang manfaat tumbuhan apotek hidup :

Tabel 4

Distribusi Pengetahuan Masyarakat

Tentang Manfaat Tanaman Obat Keluarga DiNglinggi, Klaten Selatan

\begin{tabular}{|c|c|c|c|}
\hline No & Pengetahuan & $\mathbf{F}$ & $\%$ \\
\hline 1. & Baik & 11 & 36,7 \\
\hline 2. & Cukup & 7 & 23.3 \\
\hline 3. & Kurang & 12 & 40 \\
\hline & Total & 30 & 100 \\
\hline
\end{tabular}

Berdasarkan tabel di atas dapat diketahui bahwa dari 30 responden didapatkan pengetahuan masyarakat tentang manfaat tanaman obat keluarga berada pada katagori kurang yaitu sebanyak 12 orang $(40 \%)$. 
5. Pengetahuan tentang pengolahan tanaman obat keluarga :

Tabel 5

Distribusi Pengetahuan Masyarakat Tentang PengolahanTOGA Di Nglinggi, Klaten Selatan

\begin{tabular}{|c|c|c|c|}
\hline No & Pengetahuan & $\mathbf{F}$ & $\%$ \\
\hline 1. & Baik & 19 & 63,3 \\
\hline 2. & Cukup & 6 & 20 \\
\hline 3. & Kurang & 5 & 16,7 \\
\hline & Total & 30 & 100 \\
\hline
\end{tabular}

Berdasarkan tabel di atas dapat diketahui bahwa dari 30 responden didapatkan pengetahuan masyarakat tentang pengolahan TOGA berada pada kategori baikyaitu sebanyak 19 orang $(63,3 \%)$.

6. Pengetahuan tentang efek samping tanaman obat keluarga :

\section{Tabel 6}

Distribusi Pengetahuan Masyarakat

Tentang Tanaman Obat Keluarga Di Nglinggi, Klaten Selatan

\begin{tabular}{|c|c|c|c|}
\hline No & Pengetahuan & $\mathbf{F}$ & $\%$ \\
\hline 1. & Baik & 11 & 36,6 \\
\hline 2. & Cukup & 5 & 16,7 \\
\hline 3. & Kurang & 14 & 46,7 \\
\hline & Total & 30 & 100 \\
\hline
\end{tabular}

Berdasarkan tabel di atas dapat diketahui bahwa dari 30 responden didapatkan pengetahuan masyarakat ibu tentangefek samping tanaman obat keluarga tumbuhanberada pada katagori kurang yaitu sebanyak 14 orang $(46,7 \%)$.
7. Pengetahuan ibu tentang TOGA :

Tabel 7

Distribusi Pengetahuan Masyarakat Tentang Tumbuhan Tanaman Obat Keluarga Di Nglinggi, Klaten Selatan

\begin{tabular}{llcc}
\hline No & \multicolumn{1}{c}{ Pengetahuan } & F & \% \\
\hline 1. & Baik & 4 & 13,3 \\
2. & Cukup & 17 & 56,7 \\
3. & Kurang & 9 & 30 \\
\hline \multicolumn{2}{c}{ Total } & 30 & 100 \\
\hline
\end{tabular}

Berdasarkan tabel di atas dapat diketahui bahwa dari 30 responden didapatkan pengetahuan masyarakat tentang tumbuhan tanaman obat keluarga sebagian besar berada pada katagori cukup yaitu sebanyak 17 orang $(55,5 \%)$.

\section{PEMBAHASAN}

Berdasarkan analisa data didapatkan bahwa dari 30 respon dan didapatkan pengetahuan masyarakat tentang tanaman obat keluarga sebagian besar berada pada katagori cukup yaitu sebanyak 17 orang $(56,7 \%)$,dengan rincian pengetahuan masyarakat tentang jenis tumbuhan tanaman obat keluarga sebagian besar berada pada katagori kurang yaitu sebanyak 15 orang $(50 \%)$, pengetahuan masyarakat tentang manfaat tanaman obat keluargasebagian besar berada pada katagori kurang yaitu sebanyak 11 orang $(36,7 \%)$,pengetahuan masyarakat tentang pengolahan tanaman obat keluargasebagian besar berada pada karagori baik yaitu sebanyak 19 orang $(63,3 \%)$ dan pengetahuan masyarakat tentang efek samping tanaman obat keluargasebagian besar berada pada katagori kurang yaitu sebanyak 14 orang $(46,7 \%)$ 


\section{KESIMPULAN DAN SARAN}

Kesimpulan penelitian pengetahuan masyarakat tentang TOGA dapat bermanfaat bagi kesehatan baik untuk meningkatkan kesehatan, pencegahan penyakit, penyembuhan dan pemulihan di Nglinggi, Klaten Selatan, dapat disimpulkan sebagai berikut:

1. Sebagian besar masyarakat memiliki pengetahuan yang cukup tentang tanaman obat keluarga yaitu sebanyak 17 orang $(56,7 \%)$,

2. Sebagian besarmasyarakat memiliki pengetahuan yang kurang tentang jenis tanaman obat yaitu sebanyak 15 orang $(50 \%)$.

3. Sebagian besar masyarakat memiliki pengetahuan yang baik tentang manfaat tanaman obat keluarga yaitu sebanyak 1 orang $(36,7 \%)$.

4. Sebagian besarmasyarakat memiliki pengetahuan yang baik tentang pengolahan tanaman obat keluarga yaitu sebanyak 19 orang $(63,3 \%)$.

5. Sebagian besar masyarakat memiliki pengetahuan yang kurang tentang efek samping tanaman

obat keluarga yaitu sebanyak 14 orang $(46,7 \%)$.

Saran untuk penelitian ini adalah:

1. Bagi Peneliti

Diharapkan peneliti ini dapat menambah pengetahuan, wawasan danpengalaman bagi peneliti dalam melakukan penelitian-penelitian berikutnya.

\section{Bagi Tempat Penelitian}

Diharapkan penelitian ini dapat menjadi bahan masukan/ informasi tentang hal-hal yang berhubungan dengan tanaman obat keluarga dan meningkatkan kepedulian masyarakat terhadap penanaman tanaman obat keluarga disekitar rumahnya.

\section{Bagi Institusi Pendidikan}

Diharapkan agar dapat menambah referensi pustakaan tentang tanaman obat keluarga untuk meningkatkan kesehatan, pencegahan penyakit, penyembuhan dan pemulihan, agar dapat memudahkan mahasiswa dalam mencari teori tentang tanaman obat keluarga.

\section{DAFTAR RUJUKAN}

Dalimartha, Setiawan. 1999. Atlas tumbuhan obat Indonesia. Jilid 1. Jakarta: Trubus Agriwijaya. Halaman 18-21, 36-40, 50-56, 73$77,115-119,120-125,139-144$, 146-149, 158-161.

Departemen Kesehatan Republik Indonesia. 1993. Tanaman obat keluarga. Jakarta : Departemen Kesehatan RI. Halaman 23-24, 4243, 61-66, 75-76, 80-82, 89-97, 105-108, 113-115.

Handayani, Lestari. 2002. Pemanfaatan obat tradisional untuk kesehatan usila.

http://www.tempo.co.id/medika/ar sip/112002/hor-2. 3 Mei 2007.

Jeruk http://www.iptek.net.id/ind/pd tan obat/view.php?id=131. 2 November 2007.

Mahendra, B. 2006. Panduan meracik herbal. Jakarta : Penebar Swadaya. Halaman 5-31, 47-49, 56-70. 